\title{
Produção do pimentão adubado com esterco bovino e biofertilizante
}

\author{
Evanduir N. de Araújo ${ }^{1}$, Ademar P. de Oliveira ${ }^{2}$, Lourival F. Cavalcante ${ }^{3}$, Walter E. Pereira ${ }^{3}$, \\ Noelma M. de Brito ${ }^{1}$, Cynthia M. de L. Neves ${ }^{1} \&$ Érllens É. da Silva ${ }^{1}$
}

\begin{abstract}
RESUMO
Com o objetivo de avaliar o rendimento do pimentão adubado com esterco bovino na presença e ausência do biofertilizante, conduziu-se um experimento na UFPB, Areia, PB, no período de janeiro a junho de 2004. O delineamento experimental foi de blocos casualizados, com três repetições em parcelas subdivididas. Nas parcelas se avaliaram seis doses de esterco bovino $\left(0,10,20,30,40\right.$ e $\left.50 \mathrm{t} \mathrm{ha}^{-1}\right)$ e, nas subparcelas, os efeitos das aplicações do biofertilizante no solo e via foliar e sua ausência, além de um tratamento adicional com adubação mineral e orgânica. A parcela compunha de 32 e a sub-parcela de 16 plantas, espaçadas $1,00 \times 0,50 \mathrm{~m}$. Na ausência de biofertilizante a dose estimada de $28 \mathrm{t}^{-1} \mathrm{f}^{-1}$ de esterco bovino foi responsável pela produção máxima de frutos por planta $(389 \mathrm{~g})$ e produtividade máxima de frutos comerciais $\left(7,8 t \mathrm{tha}^{-1}\right)$, enquanto na sua presença aplicado via foliar, as doses de 14,5 e 14,0 tha-1 de esterco bovino, respectivamente, proporcionaram produção máxima de frutos por planta de $485 \mathrm{~g}$ e produtividade máxima de frutos comerciais de 9,6 tha-1. Na presença de biofertilizante aplicado no solo, obteve-se produção média de 410, $6 \mathrm{~g}$ de frutos por planta e produtividade de $8,3 \mathrm{t} \mathrm{ha} \mathrm{a}^{-1}$ de frutos comerciais, em função das doses de esterco bovino. A combinação esterco bovino e biofertilizante aplicada via foliar, foi a melhor forma de fertilização orgânica no pimentão, com incrementos de 1,8 e 1,3 tha-1 a mais na produtividade de frutos, em relação apenas ao emprego de esterco bovino.
\end{abstract}

Palavras-chave: Capsicum annuum, adubação orgânica, rendimento

\section{Bell pepper yield fertilized with cattle manure and biofertilizer}

\begin{abstract}
With the objective of evaluating bell pepper fertilized with cattle manure with and without biofertilizer, an experiment was carried out from January to June 2004, in Quarts Psamment at UFPB, Areia, PB, Brazil. The experimental design was randomized block, with three replications in sub-divided plots. The plot was constituted by 32 and the sub-plot by 16 plants, spaced at $1.00 \times 0.50 \mathrm{~m}$. In the plots, six levels of cattle manure $\left(0,10,20,30,40\right.$ and $\left.50 \mathrm{t} \mathrm{ha}^{-1}\right)$ were appraised, while in the sub-plots the forms of application of the biofertilizer (with and without application of biofertilizer in the soil and spraying on the leaves) and an additional treatment with mineral and organic fertilizer. In the absence of biofertilizer, $28 \mathrm{t} \mathrm{ha-1}$ estimated level of cattle manure was responsible for maximum yield of fruits per plant $(389 \mathrm{~g})$ and for commercial fruits $(7.8 \mathrm{t} \mathrm{ha-1})$, while biofertilizer used in spray application, the levels of 14.5 and $14.0 \mathrm{t} \mathrm{ha}^{-1}$ of cattle manure, respectively, promoted maximum production of fruits per plant of $485 \mathrm{~g}$ and maximum productivity of commercial fruits of $9.6 \mathrm{tha}^{-1}$. The biofertilizer presence into the soil, promoted mean production of $410 \mathrm{~g}$ of fruits per plant and productivity of $8.3 \mathrm{tha}^{-1}$ of commercial fruits, in function of cattle manure. The combination cattle manure and biofertilizer in the leaves was the best organic fertilization form in the bell pepper, with additional of 1.8 and $1.3 \mathrm{tha}^{-1}$ in the productivity of commercial fruits, comparing with those obtained with cattle manure and biofetilizer used in the soil, respectively. There is no significance difference among organic treatments and conventional fertilization in the bell pepper productivity.
\end{abstract}

Key words: Capsicum annuum, organic fertilizer, yield

3 Depto. de Solos e Engenharia Rural, CCA/UFPB. Fone: (83) 3362-2300, ramal 297. E-mail: lofeca@cca.ufpb.br 


\section{INTRODUÇÃO}

O pimentão é bastante exigente no que diz respeito às características química e física do meio de cultivo, respondendo muito bem à adubação orgânica, sendo que excelentes produtividades podem ser obtidas através da associação de adubos orgânicos e minerais (Souza \& Bruno, 1991), porém a aplicação de adubos e corretivos na cultura do pimentão é uma prática agrícola onerosa que representa, em média, 23,4\% do custo de produção (Ribeiro et al., 2000).

A utilização de adubos orgânicos de origem animal torna-se prática útil e econômica para os pequenos e médios produtores de hortaliças, de vez que enseja melhoria na fertilidade e na conservação do solo (Galvão et al., 1999), no entanto, maiores ou menores as doses a serem utilizadas dependerão do tipo, textura, estrutura e teor de matéria orgânica no solo (Trani et al., 1997) e, quando utilizada vários anos consecutivos proporciona acúmulo de nitrogênio orgânico no solo, aumentando seu potencial de mineralização e sua disponibilidade para as plantas (Scherer, 1998). Neste sentido, Filgueira (2000) afirma que as hortaliças reagem bem a este tipo de adubação, tanto em produtividade como em qualidade dos produtos obtidos, sendo o esterco bovino a fonte mais utilizada pelos olericultores, devendo ser empregado especialmente em solos pobres em matéria orgânica. No Pimentão, Sonnenberg (1985) recomenda, nesses solos, pelo menos o emprego de $20 \mathrm{t} \mathrm{ha}^{-1}$ de esterco bovino ou 7,0 t ha $^{-1}$ de esterco de galinha.

Outra prática útil e de baixo custo é o emprego de biofertilizantes, principalmente pelo fato da crescente procura por novas tecnologias de produção que apresentem redução de custos e a preocupação com a qualidade de vida no planeta. Esses fatos, contudo, têm encorajado pesquisadores e produtores rurais a experimentarem biofertilizantes preparados a partir da digestão aeróbica ou anaeróbica de materiais orgânicos, com o adubo foliar, em substituição aos fertilizantes minerais (Fernandes et al., 2000), visto que em agricultura orgânica os mesmos são recomendados como forma de manter o equilíbrio nutricional de plantas e torná-las menos predispostas á ocorrência de pragas e de patógenos (Santos, 2001). De acordo com Santos (2001), biofertilizante é a designação dada ao efluente líquido obtido da fermentação metanogênica da matéria orgânica e água; enquanto Alves et al. (2001), o definem como resíduo final da fermentação de compostos orgânicos que contêm células vivas ou latentes de microrganismos (bactérias, leveduras, algas e fungos filamentosos) e por seus metabólicos, além de quelatos organominerais.

Em olerícolas recomenda-se o emprego de biofertilizantes por meio de pulverizações semanais, para permitir um desenvolvimento perfeito das plantas, uma vez que apresentam ciclo vegetativo e reprodutivo curto, exigindo uma complementação mais rápida e eficiente (Santos, 1992); no pimentão, entretanto, as informações sobre seu uso são bastante limitadas, o que justifica a necessidade de se realizar pesquisas para viabilizar seu emprego como fertilização alternativa já que, pela exigência nutricional das cultivares existentes no mercado, o rendimento comercial de frutos tem sido limitado pela insuficiente nutrição das plantas, mesmo em condições de solo com teor adequado de matéria orgânica (Souza, 2000).
Este trabalho foi realizado com o objetivo de avaliar o efeito de doses de esterco bovino na presença e ausência de biofertilizante, aplicados no solo e via foliar, sobre a cultura do pimentão.

\section{MATERIAL E MÉTODOS}

O trabalho foi realizado no período de janeiro a junho de 2004, na Universidade Federal da Paraíba, em Areia, PB, localizado na microrregião do Brejo Paraibano. Pela classificação de Köppen, o clima é do tipo AS' (quente e úmido), precipitação pluviométrica média anual em torno de $1.400 \mathrm{~mm}$ e temperatura média anual entre 23 e $24^{\circ} \mathrm{C}$. A temperatura média em ${ }^{\circ} \mathrm{C}$, a precipitação pluviométrica em mm e a umidade relativa em \% do período foram, respecitamente: janeiro $=23,1 ; 471 ; 89$; fevereiro $=23 ; 266$; 88; março $=23,1 ; 151 ; 63 ;$ abril $=22,9 ; 204 ; 89 ;$ maio $=22,1$; 273; 91 e junho = 20,8; 292; 92.

O solo da área experimental foi classificado como Neossolo Regolítico Psamítico típico, textura franco-arenosa (EMBRAPA, 1999). As análises químicas e físicas da camada de 0-20 cm, realizadas segundo EMBRAPA (1997), resultaram

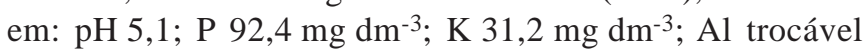
$0,0 \mathrm{cmol}_{\mathrm{C}} \mathrm{dm}^{-3} ; \mathrm{Ca}=\mathrm{Mg}=3,15 \mathrm{cmol}_{\mathrm{C}} \mathrm{dm}^{-3} ; \mathrm{H}+\mathrm{Al}=$ $1,73 \mathrm{cmol}_{\mathrm{C}} \mathrm{dm}^{-3} ; \mathrm{Na}=0,03 \mathrm{cmol}_{\mathrm{C}} \mathrm{dm}^{-3}$; matéria orgânica $=$ 9,10 $\mathrm{g} \mathrm{dm}^{-3}$; areia $=841,5 \mathrm{~g} \mathrm{~kg}^{-1}$; silte $=88,00 \mathrm{~g} \mathrm{~kg}^{-1}$; argila $=70,5 \mathrm{~g} \mathrm{~kg}^{-1}$; densidade global $=1,37 \mathrm{~g} \mathrm{~cm}^{-3}$ e densidade de partículas $=2,61 \mathrm{~g} \mathrm{~cm}^{-3}$. O esterco bovino apresentava a seguinte composição química: $\mathrm{P}_{2} \mathrm{O}_{5}=3,6 \mathrm{~g} \mathrm{~kg}^{-1} ; \mathrm{K}_{2} \mathrm{O}=$ 4,1 $\mathrm{g} \mathrm{kg}^{-1} ; \mathrm{N}=7,2 \mathrm{~g} \mathrm{dm}^{-3}$; matéria orgânica $=182,07 \mathrm{~g} \mathrm{dm}^{-3}$; e relação $\mathrm{C} / \mathrm{N}=14 / 1$ e o biofertilizante apresentou a seguinte composição de macronutrientes em g $\mathrm{L}^{-1}: \mathrm{N}=0,76$; $\mathrm{P}=0$,22; $\mathrm{K}=0,27 ; \mathrm{Ca}=0,21 ; \mathrm{Mg}=0,13$ e $\mathrm{S}=0,32$.

O delineamento experimental empregado foi de blocos casualizados, com três repetições em parcelas subdivididas; nas parcelas se avaliaram seis doses de esterco bovino $(0,10,20$, 30, 40 e $50 \mathrm{t} \mathrm{ha}^{-1}$ ) e, nas subparcelas, os efeitos das aplicações do biofertilizante no solo e via foliar e sua ausência, além de um tratamento adicional com adubação mineral e orgânica. A parcela se constituía de 32 e a subparcela de 16 plantas, espaçadas $1,00 \times 0,50 \mathrm{~m}$, todas consideradas úteis.

Nos tratamentos com e sem biofertilizante, a adubação constou apenas da aplicação das doses de esterco bovino, definidas no delineamento experimental, incorporadas nas covas, quinze dias antes do transplantio; no tratamento convencional, a adubação seguiu recomendação laboratorial, sendo fornecidos, no plantio, $30 \mathrm{t} \mathrm{ha}^{-1}$ de esterco bovino incorporada nas covas, quinze dias antes do transplantio, $40 \mathrm{~kg} \mathrm{ha}^{-1}$ de $\mathrm{N}, 150 \mathrm{~kg} \mathrm{ha}^{-1}$ de $\mathrm{P}_{2} \mathrm{O}_{5}$ e $120 \mathrm{~kg} \mathrm{ha}^{-1}$ de $\mathrm{K}_{2} \mathrm{O}$ e em cobertura, $150 \mathrm{~kg} \mathrm{ha}^{-1}$ de $\mathrm{N}$ e $180 \mathrm{~kg} \mathrm{ha}^{-1}$ de $\mathrm{K}_{2} \mathrm{O}$, parcelados em partes iguais, aos 30 e 60 dias após o transplantio. Utilizou-se como fonte de $\mathrm{N}, \mathrm{P}_{2} \mathrm{O}_{5}$ e $\mathrm{K}_{2} \mathrm{O}$, sulfato de amônio, superfosfato simples e cloreto de potássio, respectivamente.

A primeira aplicação do biofertilizante nas covas foi realizada por ocasião do transplantio, sendo aplicados $500 \mathrm{~mL} \mathrm{cova}{ }^{-1}$ na concentração de $20 \%$. A cada quinze dias 
realizaram-se aplicações no solo e via foliar, no total de cinco; antes da aplicação via foliar, o biofertilizante foi diluído e coado para evitar entupimentos no aplicador (pulverizador costal). A aplicação no solo foi realizada com vasilhame aferido para $500 \mathrm{~mL}$. O biofertilizante foi preparado conforme Santos (1992).

No plantio foram usadas mudas produzidas em sementeira convencional (Filgueira, 2000), da cultivar “All Big”, pertencente ao grupo de cultivares Casca Dura. Aos 45 dias após a semeadura, quando as mudas apresentavam em torno de oito folhas definitivas e altura média de 10 a $15 \mathrm{~cm}$, foram também transplantadas para o local definitivo.

Realizaram-se, durante a condução do experimento, os seguintes tratos culturais: irrigação pelo sistema de aspersão convencional, nos períodos de ausência de precipitação, procurando fornecer, à cultura, umidade suficiente para seu pleno desenvolvimento; capinas manuais com o auxílio de enxadas, mantendo a cultura sempre livre da concorrência de plantas daninhas. Não se realizou controle fitossanitário em decorrência da ausência de pragas e/ou doenças passíveis de prejudicar o desenvolvimento do pimentão.

As colheitas, em número de seis, foram realizadas 57 dias após o transplantio; determinaram-se a produção de frutos comerciais por planta e a produtividade e se consideraram frutos comerciais, aqueles sem defeitos e com peso superior a $70 \mathrm{~g}$ (Filgueria, 2000). Os resultados foram submetidos a análises de variância e de regressão, com significância testada através do teste $\mathrm{F}$, e a comparação das médias pelo Teste de Tukey a 5\% de probabilidade, utilizando-se o Software SAEG (2000).

\section{RESULTADOS E DISCUSSÃO}

A produção de frutos por planta e a produtividade de frutos comerciais no pimentão, foram influenciadas $(\mathrm{P}<0,01)$, pelas doses de esterco bovino e sua interação com o biofertilizante. No desdobramento da interação referente a cada característica as médias para a produção de frutos comerciais por planta e para a produtividade de frutos comerciais, em função das doses de esterco bovino na ausência de biofertilizante e na sua presença, aplicado via foliar, se ajustaram a modelos quadráticos de regressão (Figuras 1 e 2).

Na presença do biofertilizante aplicado no solo, a produção de frutos por planta e a produtividade de frutos comerciais não sofreram alterações significativas das doses de esterco bovino, com médias 389 g e 7,8 t ha ${ }^{-1}$, respectivamente, em função do emprego de esterco bovino. Na presença do biofertilizante, aplicado via foliar, a produção de frutos comerciais por planta (485 g) e a produtividade máxima de frutos comerciais $\left(9,6 \mathrm{t} \mathrm{ha}^{-1}\right)$, foram obtidas, respectivamente, com 14,5 e 14,0 t ha $^{-1}$ de esterco bovino, mas quando aplicado no solo, sua produção média foi de $410 \mathrm{~g}$ de frutos por planta e produtividade de $8,3 \mathrm{tha}^{-1}$ de frutos comerciais, em função das doses de esterco bovino.

A resposta do pimentão quanto a produção de frutos por planta e a produtividade de frutos comerciais, em função do emprego de esterco bovino na ausência do biofertilizante,

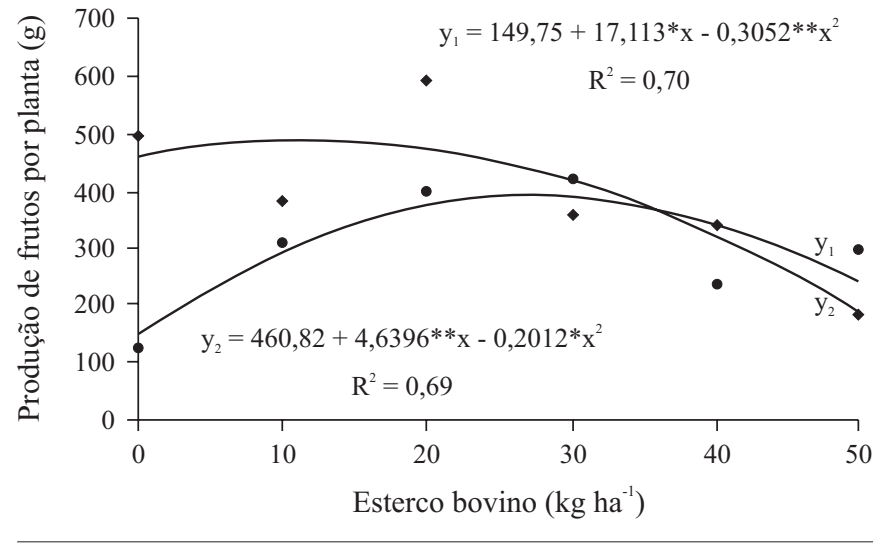

Figura 1. Produção de frutos comerciais por planta de pimentão, em função das doses de esterco bovino, na ausência $\left(\mathrm{y}_{1}\right)$ e presença $\left(\mathrm{y}_{2}\right)$ da aplicação foliar de biofertilizante. CCA-UFPB, Areia, PB, 2004

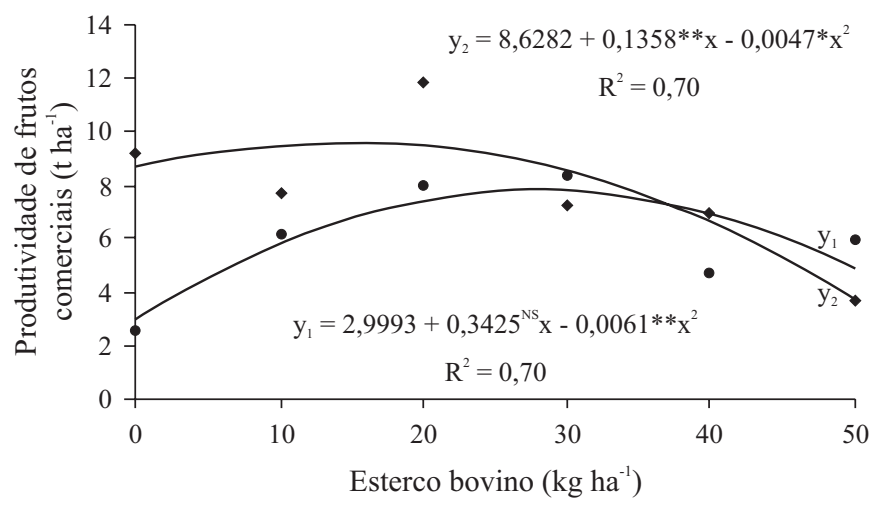

Figura 2. Produção de frutos comerciais de pimentão, em função das doses de esterco bovino na ausência $\left(y_{1}\right)$ e presença $\left(y_{2}\right)$ da aplicação foliar de biofertilizante. CCA-UFPB, Areia-PB, 2004

pode estar relacionada ao fato de que quantidades adequadas de esterco bovino de boa qualidade podem ser capazes de suprir as necessidades das plantas em macronutrientes, devido à elevação dos teores de N, P e K disponíveis, sendo o potássio o elemento cujo teor atinge valores mais elevados no solo, pelo uso contínuo (Camargo, 1984; Raij et al., 1985), além de propiciar melhoria das condições físicas do solo, tornando esses elementos altamente disponíveis aos vegetais (Varanine et al., 1993). Barbosa (2001) e Leal \& Silva (2002), obtiveram elevação na produção do pimentão, em função do emprego de esterco bovino.

O biofertilizante aplicado via foliar, foi o que proporcionou melhor interação com as doses de esterco bovino, resultando em incrementos na produtividade de frutos comerciais de 1,3 e 1,8 t ha-1 em relação àquelas obtidas apenas com esterco bovino e sua aplicação no solo, respectivamente, o que pode indicar que a aplicação de biofertilizante via foliar atendeu às exigências nutricionais do pimentão, em função do fornecimento equilibrado de macro e micronutrientes, o que permitiu desenvolver o seu potencial genético produtivo (Pereira \& Mello, 2002), de vez que possui nutrientes mais facilmente absorvíveis pelas plantas, quando comparados a outros adubos orgânicos, além de possuir granulação mais fina, facilitando melhorias na estruturação do solo (Silva 
Filho et al., 1983). Souza \& Resende (2003), relatam que uma das principais alternativas para a suplementação de nutrientes na produção orgânica de hortaliças é a utilização de fertilizantes orgânicos líquidos.

As doses de esterco bovino na presença do biofertilizante via foliar, necessárias para proporcionar elevação na produção de frutos por planta e na produtividade de frutos comerciais, foram praticamente 50\% inferiores àquela necessária na ausência do biofertilizante. Tais resultados estão relacionados não somente com a melhoria geral da fertilidade, mas, também, com melhor absorção de nutrientes. O fornecimento adequado de nutrientes, como o $\mathrm{N}$, aliado a outros fatores, expande a área fotossintética, assegura o desenvolvimento das plantas pelo crescimento vegetativo e eleva o potencial produtivo das culturas (Filgueira, 2000).

Mesmo ocorrendo ausência de resposta significativa na aplicação de biofertilizante no solo sobre a produtividade de frutos comerciais, em função da elevação das doses de esterco bovino, ela foi superior à obtida apenas com esterco bovino, o que pode indicar que o biofertilizante aplicado desta forma, também é eficiente em aumentar a produção no pimentão.

A queda da produção de frutos por planta e da produtividade de frutos comerciais, em função das doses de esterco bovino na ausência de biofertilizante e na sua presença, aplicado via foliar, acima daquelas responsáveis pelos máximos valores, pode indicar que, possivelmente, o aumento das doses de esterco bovino proporcionou desequilíbrio nutricional ao pimentão, isto porque doses elevadas desse adubo podem causar desbalanço nutricional e, conseqüentemente, redução da produtividade da cultura (Silva et al., 2000). De acordo com Primavesi (1989), o equilíbrio entre os elementos nutritivos proporciona maiores produtividades que maiores quantidades de macronutrientes isoladamente.

Com relação às comparações de média para a produção de frutos comerciais por planta e para a produtividade de frutos comerciais, em função do desdobramento entre esterco bovino e biofertilizante versus adubação convencional, não houve diferença significativa entre eles (Tabela 1); contudo, previa-se resposta significativa do pimentão à adubação convencional porque, segundo Filgueira (2000), esta hortaliça responde bem ao emprego de nitrogênio, fósforo e potássio. Alguns autores verificaram respostas do pimentão ao emprego de adubos minerais. Vieites (1998) obteve elevação na produção de frutos, em função do emprego de potássio e Silva et al. (1999), em função do fornecimento de nitrogênio e potássio; portanto, a ausência de resposta do pimentão à adubação convencional, talvez possa estar relacionada às perdas de nutrientes do solo, através de lixiviação em função do excesso de precipitação ocorrida durante a execução da pesquisa o que, de acordo com Melo et al. (2000) a adubação mineral apresenta a inconveniência de ser facilmente lixiviada da solução do solo, sobretudo o nitrogênio. Leite Júnior (2001), também obteve menor produção de frutos no pimentão quando cultivado em período de alta precipitação.

Também, a ausência de diferença entre os tratamentos esterco bovino e biofertilizante e adubação convencional, pode indicar que a associação desses fertilizantes orgâni- cos pode ser recomendada para a fertilização não-convencional no pimentão, pelo fato do esterco bovino e o biofertilizante fornecerem $\mathrm{N}, \mathrm{P}$ e $\mathrm{K}$ e outros elementos minerais gradualmente, aumentando a velocidade de infiltração de água, melhoria das propriedades físicas do solo e aumento da produção (Filgueira, 2000). Em cenoura, Viana et al. (2003) ao avaliarem a adubação verde, composto orgânico e biofertilizante notaram que o biofertilizante aplicado via foliar favoreceu o desenvolvimento vegetativo e, no solo, ocorreu maior produção. No pimentão, Paes (2003) verificou, na região de Areia, PB, resposta positiva sobre o rendimento de frutos, em função do emprego do biofertilizante de urina de vaca.

Tabela 1. Produção de frutos comerciais por planta e produção de frutos comerciais, em função do desdobramento entre esterco bovino e biofertilizante versus adubação convencional. CCA-UFPB, Areia, PB, 2004

\begin{tabular}{lcc}
\hline Tratamentos & $\begin{array}{c}\text { Produção de frutos } \\
\text { planta- }^{-1} \mathbf{( g )}\end{array}$ & $\begin{array}{c}\text { Produção de frutos } \\
\text { comerciais }\left(\mathrm{t} \mathbf{h}^{-1}\right)\end{array}$ \\
Esterco bovino e biofertilizante & $365 \mathrm{a}$ & $7,31 \mathrm{a}$ \\
Adubação convencional & $284 \mathrm{a}$ & $5,69 \mathrm{a}$ \\
$\mathrm{CV}(\%)$ & 23,91 & 25,81 \\
\hline
\end{tabular}

Médias seguidas de mesma letra na coluna não diferem estatisticamente a $5 \%$ de probabilidade pelo teste $\mathrm{F}$

\section{CONCLUSÕES}

1. O biofertilizante bovino, aplicado de forma isolada ou associado com matéria orgânica, pode ser utilizado como alternativa para fertilização não-convencional no pimentão.

2. O biofertilizante aplicado via foliar proporcionou melhor interação com as doses de esterco bovino, resultando em incrementos na produtividade de frutos comerciais no pimentão.

3. A aplicação de biofertilizante via foliar atendeu às exigências nutricionais do pimentão.

\section{LITERATURA CITADA}

Alves, S. B.; Medeiros, M. B.; Tamai, M. A.; Lopes, R. B. Trofobiose e microrganismos na proteção de plantas: Biofertilizantes e entomopatógenos na citricultura orgânica. Biotecnologia Ciência \& Desenvolvimento, n.21, p.16-21, 2001.

Barbosa, J. K. A. Efeito da adubação orgânica com esterco bovino e suíno na cultura do pimentão (Capsicum annuum L.). Areia: UFPB, 2001, 30p. Trabalho Conclusão Curso

EMBRAPA - Empresa Brasileira de Pesquisa Agropecuária. Serviço Nacional de Levantamento e Conservação do Solo. Manual de métodos de análise de solo. Rio de Janeiro: Ministério da Agricultura, 1997. 212p.

EMBRAPA - Empresa Brasileira de Pesquisa Agropecuária. Empresa Brasileira de Pesquisa Agropecuária - Centro Nacional de Pesquisa de Solos. Sistema Brasileiro de Classificação de Solos. Brasília: Produções de Informações, 1999. 412p.

Camargo, L. de S. As hortaliças e seu cultivo. Campinas: Fundação Cargill, p.28-29, 1984.

R. Bras. Eng. Agríc. Ambiental, v.11, n.5, p.466-470, 2007. 
Fernandes, M. C. A.; Leal, M. A. A.; Ribeiro, R. L. D.; Araújo, M. L.; Almeida, D. L. Cultivo protegido do tomateiro sob manejo orgânico. A lavoura. Rio de Janeiro, v.3, n.634, p.44-45, 2000.

Filgueira, F. A. R. Manual de olericultura: Agrotecnologia moderna na produção e comercialização de hortaliças. Viçosa, 2000, 402p.

Galvão, J. C. C.; Miranda, G. V.; Santos, I. C. Adubação orgânica. Revista Cultivar, São Paulo, v.2 n.9, p.38-41, 1999.

Leal, M. A. A.; Silva, V. V. Comparação entre esterco de curral e cama de aviário como adubação de cova e de cobertura em pimentão orgânico cultivado em estufa e a céu aberto. In: Congresso Brasileiro de Olericultura, 42, 2002, Uberlândia. Resumos... Uberlândia: SOB, 2002, p.122.

Leite Júnior, G. P. Redução ou aumento das doses de nitrogênio e potássio aplicadas ao pimentão via fertirrigação à adubação convencional. Areia: UFPB, 2001. 65p. Dissertação Mestrado

Melo, W. J.; Marques, M. O.; Melo, V. P.; Cintra, A. A. D. Uso de resíduos em hortaliças e impacto ambiental. In: Congresso Brasileiro de Olericultura, 41, São Pedro. Resumo... São Pedro: SOB, 2000, p.32.

Paes, R. A. Rendimento do pimentão (Capsicum annuum L.) cultivado com urina de vaca e adubação mineral. Areia: UFPB, 2003. 65p. Dissertação Mestrado

Pereira, H. S.; Mello, S. C. Aplicação de fertilizantes foliares na nutrição e produção do pimentão e do tomateiro. Horticultura Brasileira, Brasília, v.20, n.4, p.597-600, 2002.

Primavesi, A. Manejo biológico do solo: A agricultura em regiões tropicais. 8.ed. São Paulo: Nobel, 1989, 541p.

Raij, B. van; Silva, M. N.; Bataglia, O. C.; Quagio, J. A. Recomendações de adubação e calagem para o Estado de São Paulo. Campinas: IAC, 1985, 170p. Boletim, 100

Ribeiro, G. L.; Lopes, J. C.; Martins Filho, S.; Ramalho, S. S. Adubação orgânica na produção do pimentão. Horticultura Brasileira, Brasília, v.18, n.2, p.134-137, 2000.

SAEG. Sistema para Análise Estatística; versão 8.0. Viçosa: Fundação Artur Bernardes, 2000.

Santos, A. C. V. Biofertilizante líquido, o defensivo da natureza. Niterói: EMATER, 1992. 16p. Agropecuária Fluminense, 8

Santos, A. C. V. A ação múltipla do biofertilizante líquido como ferti fitoprotetor em lavouras comerciais. In: Hein, M. (org). Encontro de Processos de Proteção de Plantas: Controle ecológico de pragas e doenças, 1, 2001, Botucatu. Resumos... Botucatu: Agroecológica, 2001. p.91-96.
Scherer, E. E. Utilização de estercos suínos como fonte de nitrogênio: bases para a adubação dos sistemas milho/feijão e feijão/milho, em cultivos de sucessão. Florianópolis: EPAGRI, 1998. 49p. Boletim Técnico, 99

Silva, F. N.; Maia, S. S. S.; Oliveira, M. Doses de matéria orgânica na produtividade da cultura da alface em solo eutrófico na região de Mossoró. In: Congresso Brasileiro de Olericultura, 41, 2000, São Pedro, Resumos... São Pedro: SOB, 2000, p.56-57, 2000.

Silva, M. A. G.; Boaretto, A. E.; Melo, A. M. T.; Fernandes, H. M. G.; Scivittaro, W. B. Rendimento e qualidade de frutos de pimentão cultivado em ambiente protegido em função do nitrogênio e potássio aplicados em cobertura. Scientia Agrícola, Piracicaba, v.56, n.4, p.1119-1207, 1999.

Silva Filho, L. M.; Prakasan, K.; Prakassan, G. Estudo comparativo entre biofertilizantes e adubos orgânicos convencionais. Revista Agropecuária Técnica, Areia, v.4. n.3, p.16-24. 1983.

Sonnenberg, P. E. Olericultura especial - II. 3.ed. Goiânia: UFG - EAV, 1985, p.149.

Souza, J. L. Nutrição orgânica com biofertilizantes foliares na cultura do pimentão em sistema orgânico. In: Congresso Brasileiro de Olericultura, 41, 2000, São Pedro. Resumos... São Pedro: SOB, 2000, p.828-829, 2000.

Souza, J. L.; Resende, P. Manual de horticultura orgânica. Viçosa: Aprenda Fácil, 2003, 564p.

Souza, W. P.; Bruno, G. B. Efeito da adubação organomineral sobre a produção de pimentão. Horticultura Brasileira, Brasília, v.9, n.1, p.60-62. 1991.

Trani, P. E.; Tavares, M.; Siqueira, W. J.; Santos, R. R.; Bisão. L. L.; Lisbão, R. S. Cultura do alho. Recomendação para seu cultivo no Estado de São Paulo. Campinas: IAC, 1997, 26p.

Varanine, Z.; Pinton, R.; Biase, M. G.; Astolfi, S.; Maggioni, A. Low molecular weight humic substances stimulate $\mathrm{H}^{+}$-ATPase activity of plasma membrane vesicles isolated from oat (Avena sativa L.) roots. Plant and Soil, v.153, n.3, p.61-69, 1993.

Viana, J. V.; Bruno, R. L. A.; Silva, V. F.; Santos, G. P.; Araújo Filho, J. O. T. Produção de cenoura (Daucus carota L.) sob diferentes fontes de adubação. In: Congresso Brasileiro de Olericultura, 43, Recife. Resumo... Recife: SOB, 2003, p.23.

Vieites, R. L. Efeitos da adubação com manipueira sobre o rendimento e qualidade dos frutos de tomate. Pesquisa Agropecuária Brasileira, Brasília, v.33, n.8, p.45-47, 1998. 